\title{
Defining Reservoir Quality Relationships: How Important Are Overburden and Klinkenberg Corrections?
}

\author{
Tuan Gia Hoang1, Peter Behrenbruch², Minh Triet Do Huu ${ }^{2}$ \\ ${ }^{1}$ Australian School of Petroleum, University of Adelaide, Adelaide, Australia \\ ${ }^{2}$ Bear and Brook Consulting Pty Ltd., Brisbane, Australia \\ Email: tuan.hoang@adelaide.edu.au,peter.behrenbruch@bearnbrook.com,phil.dohuu@bearnbrook.com
}

How to cite this paper: Hoang, T.G., Behrenbruch, P. and Huu, M.T.D. (2017) Defining Reservoir Quality Relationships: How Important Are Overburden and Klinkenberg Corrections? Journal of Geoscience and Environment Protection, 5, 86-96. https://doi.org/10.4236/gep.2017.52007

Received: October 14, 2016 Accepted: February 7, 2017 Published: February 14, 2017

\begin{abstract}
Reservoir quality from cored intervals has traditionally been described by grouping similar intervals according to rock type. The main shortcoming of this static modelling approach is that it lacks clarity and it is not conducive for setting up a dynamic simulation model. The alternative is to use a modelling approach based on Hydraulic Flow Zone Units (HFZUs). First proposed in the late 1980s and extensively published in the early 1990s such formulation uses the well-known Carman-Kozeny (C-K) equation. More recently, this approach has been extended to cover a wider range of geological formations with diverse pore structure types. In using a HFZU approach, a preprocessing step is customarily undertaken to first overburden correct the data and where necessary also to correct for the Klinkenberg effect (lower permeability formations, lab testing with gas). The study presented compares corrected and uncorrected data sets, to see if correction alters the overall outcome of HFZU analysis. Specifically, data sets are compared at three different conditions: ambient, overburden (only) corrected and finally data that has been corrected for both, overburden and Klinkenberg effects. In all cases it is the Flow Zone Indicator (FZI), an index representative of formation quality that is tracked, together with the type of relationship. Several comparative analysis examples are given for diverse formations. The results show that uncorrected data can yield a different correlation and FZI, especially for intervals that include low permeability samples. Results indicate that Overburden and Klinkenberg corrections should be applied before HFZU analysis.
\end{abstract}

\section{Keywords}

Overburden Correction, Klinkenberg Correction, Gas Slippage,

Hydraulic Flow Zone 


\section{Introduction}

Hydraulic Flow Zone Unit analysis was first proposed in the late 1980s and in the early 1990s several definitive papers were published [1] [2]. The formulation for geological zonation is described in the next section, based firstly on the Carman-Kozeny equation [3] [4] [5], and subsequently this formulation was extended by Nooruddin et al. [6], to be able to handle more diverse geological formations.

Before conducting geological zonation using a HFZU approach it is important to make environmental corrections (for pressure and fluids), in order that valid parameters may be derived for dynamic reservoir simulation, effectively describing in-situ reservoir conditions. In particular if Special Core Analysis (SCAL) plugs are utilised (plugs used for capillary pressure and relative permeability measurement), all Routine Core Analysis (RCA) plugs need to be at least "overburden" corrected, a process described in detail below.

\section{Hydraulic Flow Zone Unit Formulation: Carman-Kozeny Equation}

The initial purpose of the well-known Carman-Kozeny equation was to predict permeability as a function of pore structure parameters. However, the equation is quite complex and difficult to handle. The development of the final equation was a development over two decades, first by Kozeny and then later refined by Carman:

$$
\text { Kozeny equation: } k=\frac{1}{H_{c}} \frac{\phi_{e}^{3}}{\left(1-\phi_{e}\right)^{2}}
$$

where the pore characteristics parameter $H_{c}$ has a value of $2-7$.

$$
\text { Carman-Kozeny equation: } k=\frac{\phi_{e}^{3}}{\left(1-\phi_{e}\right)^{2}}\left(\frac{1}{F_{s} \tau^{2} S_{g v}^{2}}\right)
$$

For definition of variables, see the Nomenclature towards the end of the document.

More recently this formulation was modified to be suitable for hydraulic zonation, see for example Amaefule et al. 1993 [2], introducing concepts of Reservoir Quality Index (RQI) and Flow Zone Indicator (FZI). Such modification to the $\mathrm{C}-\mathrm{K}$ equation, is useful for studying variation in reservoir quality of geological intervals. This approach may be used for optimal zonation of a cored interval based on geological and fluid flow properties, so called Hydraulic Flow Zone Unit (HFZU) analysis and for subsequent prediction of average base parameters (permeability and porosity) as well as special core analysis parameters (capillary pressure and relative permeability relationships) for every HFZU identified. The HFZU formulation has been successfully applied to all types of clastic and carbonate formations, as long as they do not contain significant natural fractures. The new formulation may be summarised as follows:

$$
\log R Q I=\log \phi_{Z}+\log F Z I
$$

where: 
Reservoir Quality Index $R Q I(\mu m)=0.0314 \sqrt{\frac{k(m d)}{\phi_{e}}}$

Porosity Group $\phi_{z}=\frac{\phi_{e}}{1-\phi_{e}}$

Flow Zone Indicator $F Z I(\mu m)=\left(\sqrt{F_{s}} \tau S_{g v}\right)^{-1}$

In 2011, Nooruddin et al. proposed a modification to the C-K equation, incorporating a lithology factor "a" and cementation exponent [6]. The model was applied to a carbonate reservoir in Saudi Arabia and showed good results. The modified equation by Nooruddin et al. is given as:

$$
k=\frac{\phi_{e}^{2 m+1}}{\left(1-\phi_{e}\right)^{2}}\left(\frac{1}{F_{s} a^{2} S_{g v}^{2}}\right)
$$

Equation (7) may be used to form a modified HFZU formulation, extending the original formulation by Amaefule et al. [2]:

$$
\log R Q I=\log \left(\phi_{z} * \phi^{m-1}\right)+\log \left(F Z I_{m}\right)
$$

where:

$$
\text { Modified Flow Zone Indicator } F Z I_{m}(\mu m)=\left(\sqrt{F_{s}} a S_{g v}\right)^{-1}
$$

If a formation interval has a cementation factor exponent (m) of 1, Equation (8) becomes identical to Equation (3).

The first step in HFZU analysis is to choose an appropriate interval for analysis based on geological description (deposition and facie). Grain size and sorting (related to pore throat size and variation) are also useful to consider, if they are available. It should be noted that FZI is also a measure of grain size and the determination of this parameter for each plug, as well as its variation with depth are very indicative of quality changes for a particular formation interval. For some interesting case histories untilising the above mentioned methodology see for examples [7] [8] [9].

To determine the actual relationship for a chosen interval, all data points for the interval are plotted on a $\log (\mathrm{RQI})$ versus $\log (\mathrm{PG})$ graph. Before proceeding further, the data should be quality checked for erroneous values, after which a cut-off may be applied to identify non-net sub-zones. The final step before establishing a relationship is to identify outliers (data that scatters widely from a trend) and such data may be removed if justified. A line of best fit is drawn over the remaining, selected points. If the goodness of fit, indicated by $\mathrm{R}^{2}$ is over 0.5 and the slope is between 0.75 and 1.25 , the zone is $\mathrm{C}-\mathrm{K}$ compliant. If $\mathrm{R}^{2}$ is over 0.5 and the slope is greater than 1.25 , the interval is $\mathrm{C}-\mathrm{K}$ non-compliant. A slope significantly less than unity (say less than 0.75 ) has no physical meaning and is typically observed for a statistically insignificant data set of very few points. For a full treatment of various geological situations, including $\mathrm{C}-\mathrm{K}$ non-compliant zones, see [10].

Figure 1 is an example of a $\mathrm{C}-\mathrm{K}$ compliant interval with $\mathrm{R}^{2}$ of 0.88 and slope of 1.04. The C-K line has also been "reverse" modelled into a curved relationship in the lower, conventional plot. Figure 2 is an example of a C-K non-compliant 

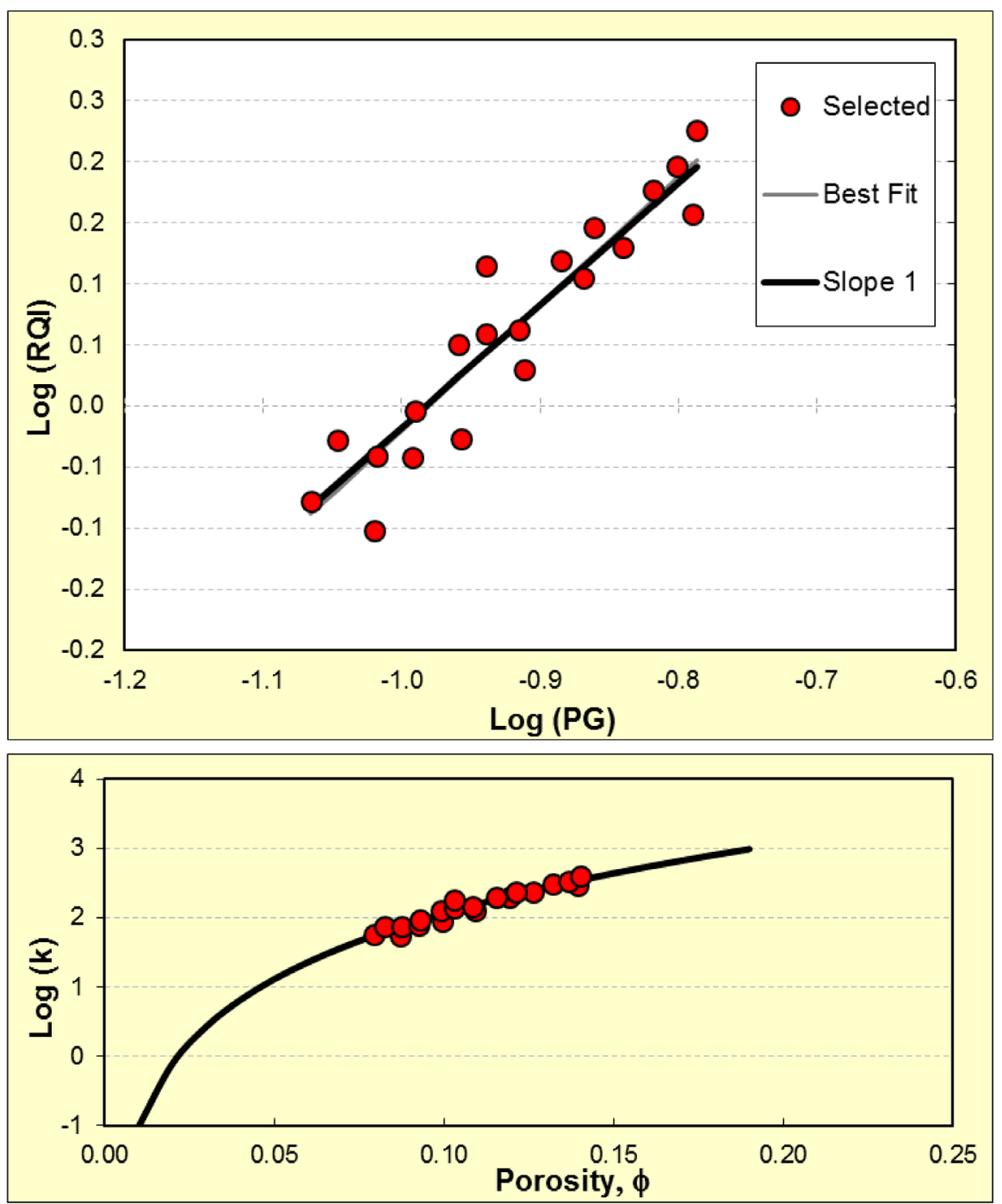

Figure 1. An example of a Carman-Kozeny compliant zone.

interval with $\mathrm{R}^{2}$ of 0.92 and slope of 2.99 .

\section{Overburden Correction}

Laboratory and the in-situ reservoir condition may differ. Typically, most RCA samples are measured in the lab at ambient conditions, while a small number are also measured at elevated pressure, so called Overburden (OB) conditions. The choice is mainly cost related, where ambient samples are significantly less costly. In order to make appropriate use of all measured data, correlations for permeability and porosity need to be established for the smaller data set; such relationships are subsequently used to correct the majority of ambient data. As demonstrated below, this correction should ideally be applied before performing HFZU analysis. From analysing of many tests, it could be verified that the most suitable relationships are Linear and Power. It should be mentioned that these correlations are not universal; each data set requires specific parameters.

Figures 3-6 show examples of Linear and Power, OB correction relationships 

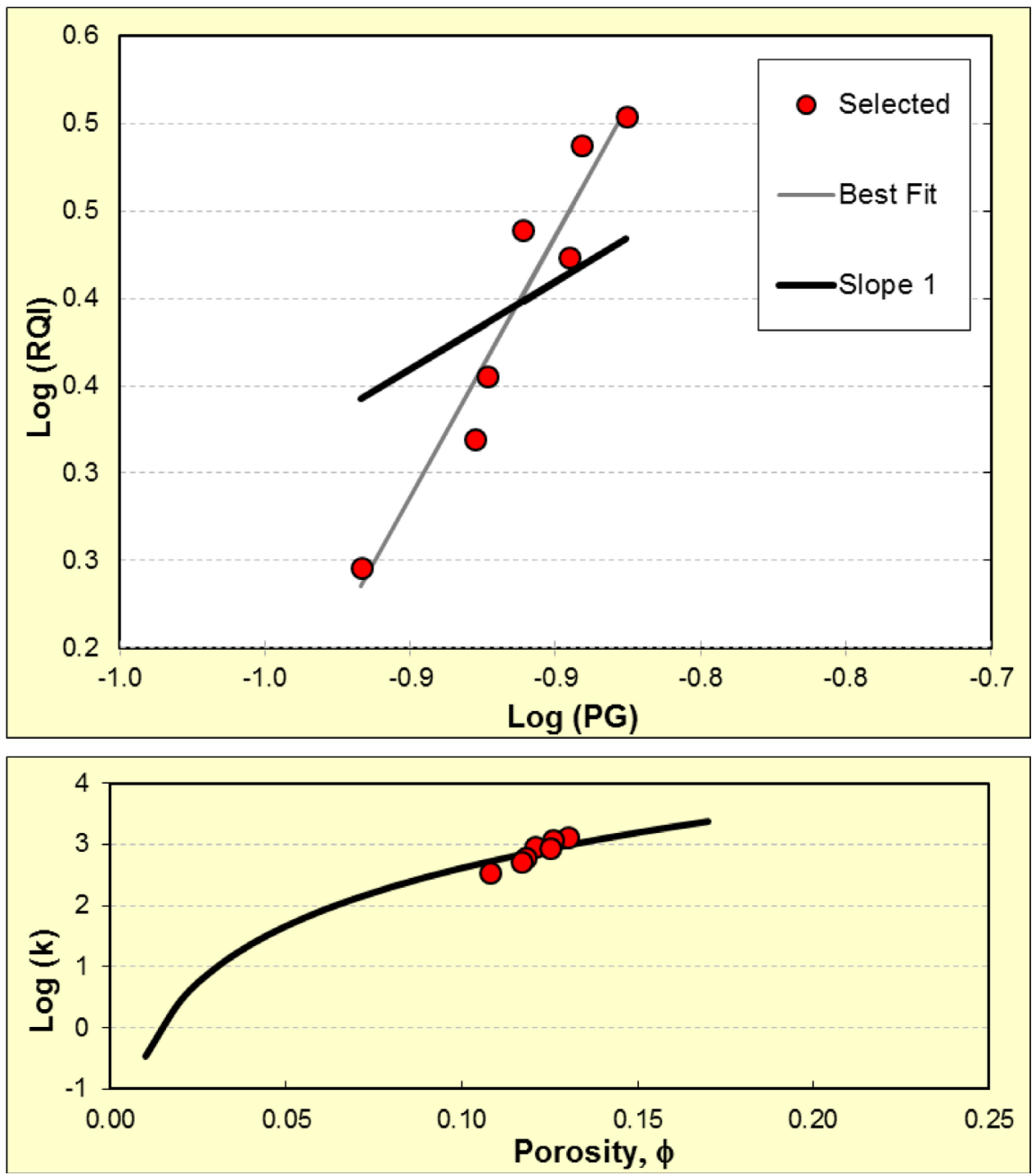

Figure 2. An example of a Carman-Kozeny non-compliant zone.

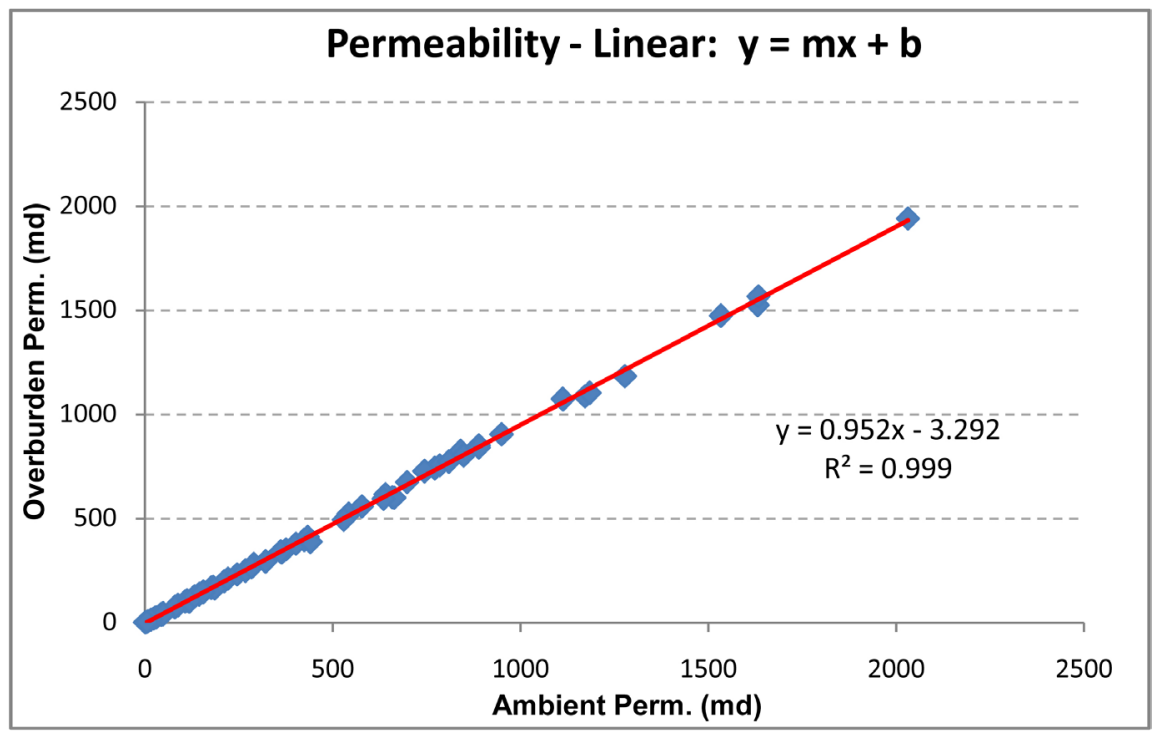

Figure 3. Linear OB correction for permeability for a specific data set.

for a specific data set. In this particular case, results suggest that the most 


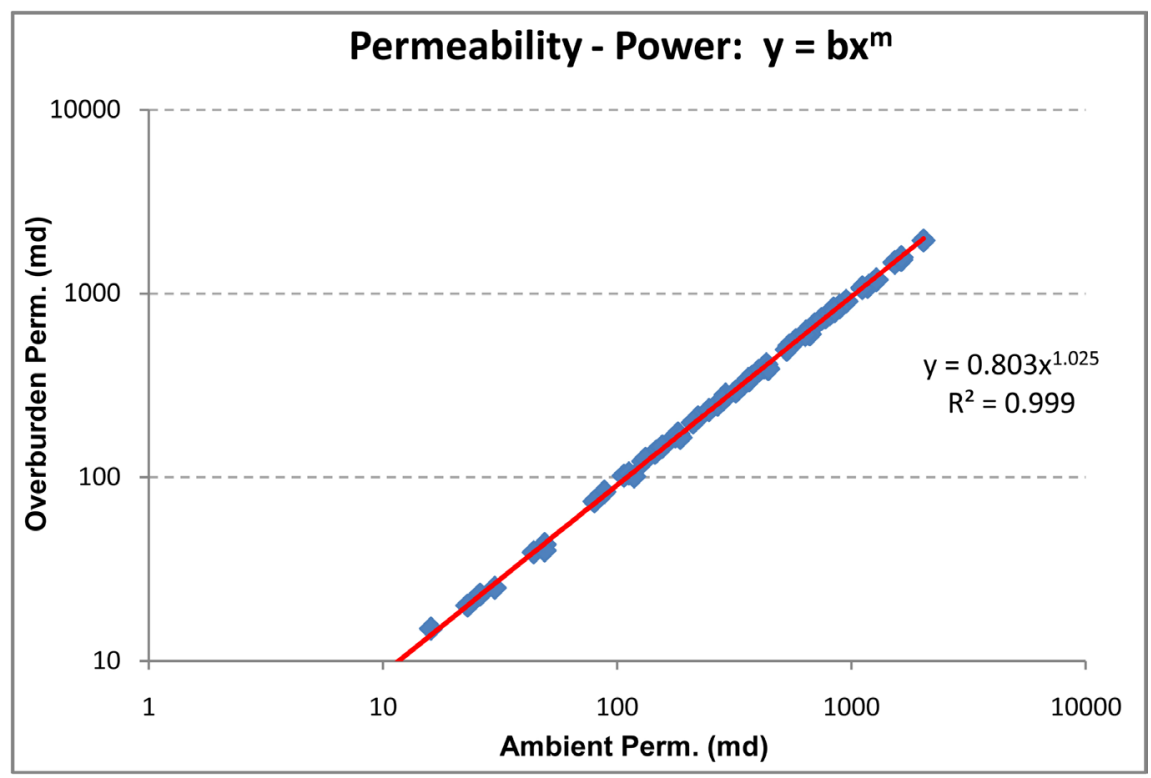

Figure 4. Power OB correction for permeability for a specific data set.

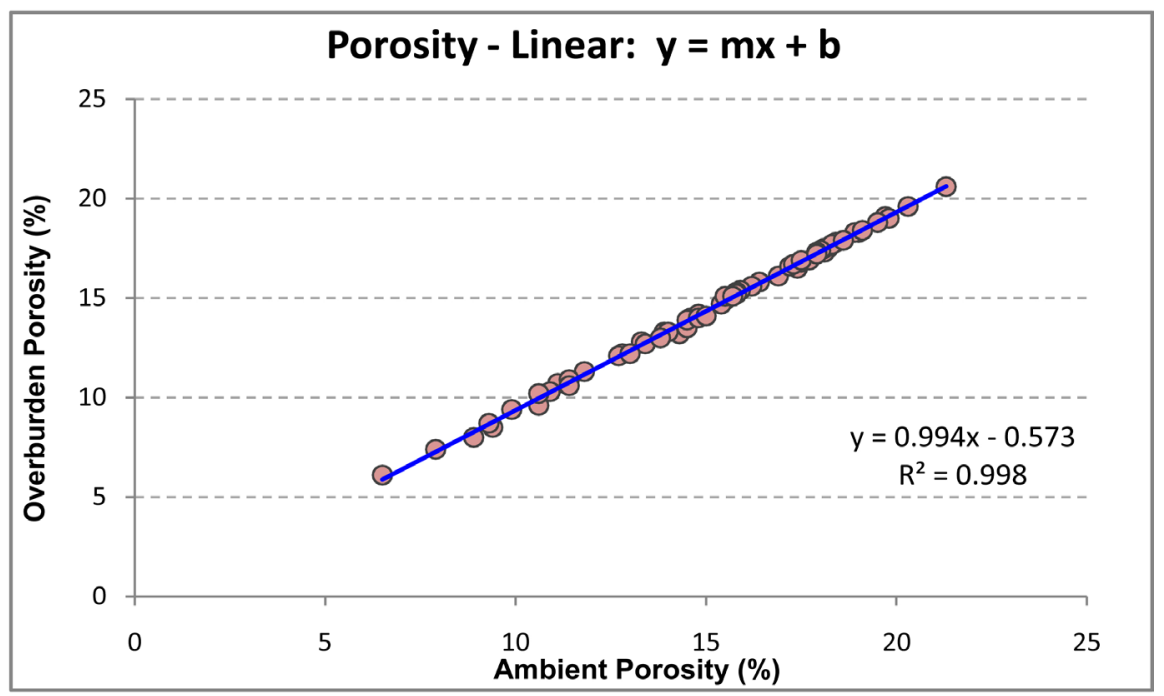

Figure 5. Linear OB correction for porosity for a specific data set.

suitable correlation for permeability is Linear and for porosity it is Power, based on $\mathrm{R}^{2}$ and the number of points (outliers) omitted but there is relatively little difference in accuracy in this particular case.

OB correction tends to decrease both permeability and porosity data simultaneously, leading to a modification in FZI value but not the HFZU correlation. Figure 7 shows a conceptual example for a small interval, indicating a shift in $\mathrm{C}-\mathrm{K}$ space, $\log$ (RQI) vs. $\log$ (FZI) as a result of OB correction. Only the position of the $\mathrm{C}-\mathrm{K}$ line is effected by $\mathrm{OB}$ correction, the slope remains unchanged.

\section{Klinkenberg Correction}

A second correction (permeability only) may need to be performed in certain cases, usually subsequently to $\mathrm{OB}$ correction, correcting for the so called 


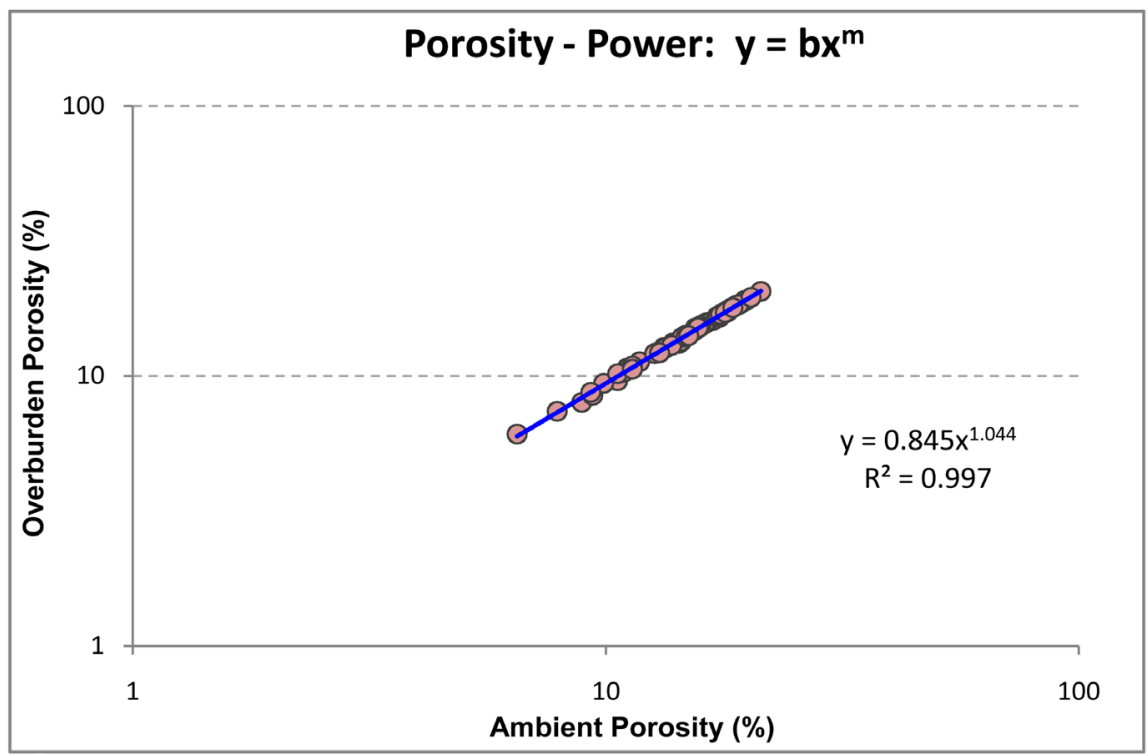

Figure 6. Power OB correction for porosity for a specific data set.

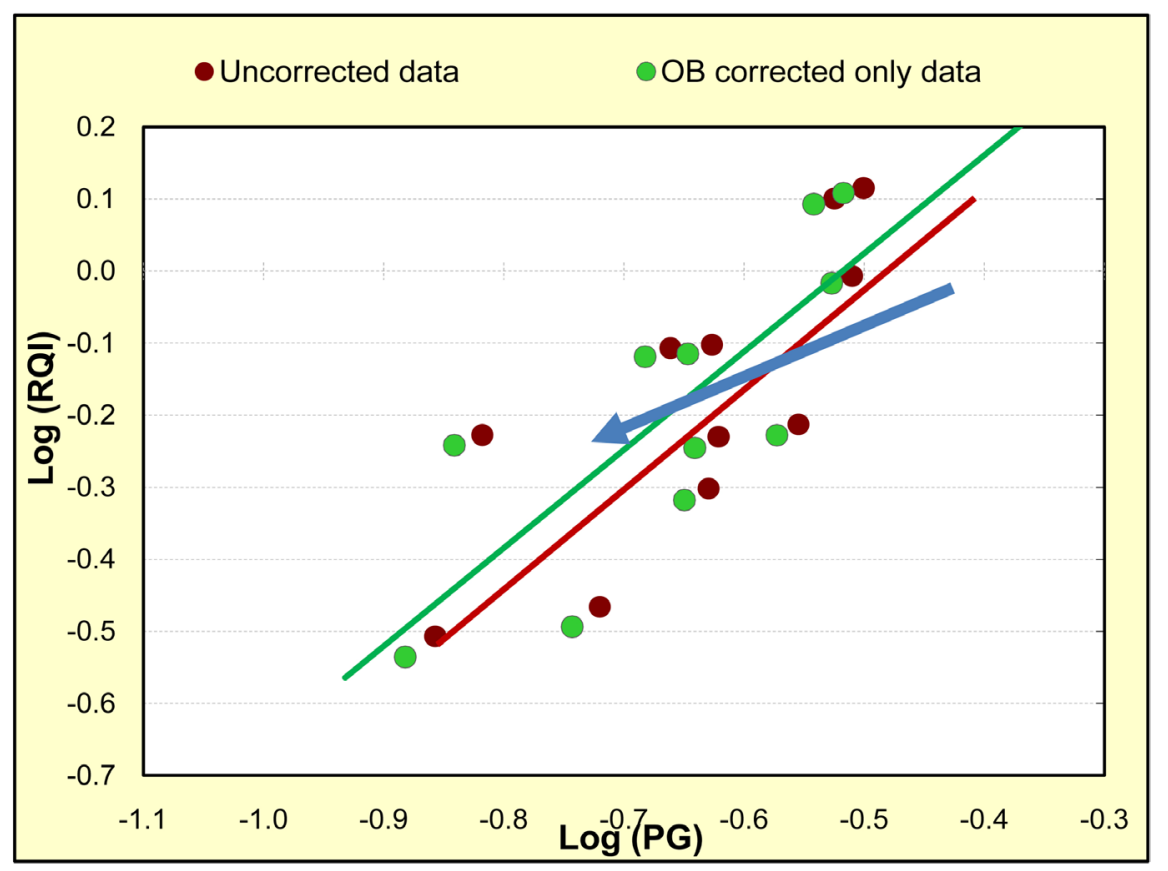

Figure 7. Conceptual example showing the effect of OB correction on HFZU analysis.

Klinkenberg effect, 1941 [11]. Permeability measurements using gas tend to overestimate the true core permeability due to a gas slippage effect. Such correction may be based on laboratory measurements or be applied by using correlations from the literature. Klinkenberg conducted various tests on this phenomenon and concluded that three key factors are of influence: rock properties, the mean laboratory core pressure and the type of gas utilised for testing. For a more recent discussion on Klinkenberg type of corrections see Florence et al. 2009 [12]. In a recent study to be published by the authors, Hoang et al., 2017 [13], it was found that the so called square root model accounts for all of these 
factors and is the most suitable method to correct laboratory permeability gas measurements.

The Klinkenberg effect is more severe for low permeability samples (also at low pressure), while for samples greater than $1000 \mathrm{mD}$, the effect is negligible. Consequently, for samples with a wide range of permeability, the Klinkenberg correction not only decreases FZI values but also changes the slope of HFZU relationships. Figure 8 shows the effect of Klinkenberg correction for a conceptual, wide permeability range interval, indicating both, a decrease in FZI and a change in slope.

\section{Laminaria-2 Case History}

The Laminaria oil field is located in the Timor Sea and a very comprehensive RCA data set is available for the Laminaria-2 (Lam-2) well: 361 measured plug samples covering an interval of $125.4 \mathrm{~m}$. Ambient measurements were performed for all samples, horizontal air permeability and helium porosity at 400 psig. A sub-set of 174 samples were chosen for OB testing at 3950 psig. Before conducting HFZU analysis, all ambient data were corrected to OB conditions using a Power correlation for permeability and Linear relationship for porosity. The correlation equations used for correction are:

$$
\begin{aligned}
& k_{O B}=0.7995\left(k_{A m b}\right)^{1.0267} \\
& \phi_{O B}=1.009 \phi_{A m b}+0.0053
\end{aligned}
$$

Klinkenberg correction was subsequently applied using the square-root model, Florence et al. 2007, [12], for air at mean core pressure of 25 psig.

A detailed HFZU analysis was performed for the Lam-2 well after application

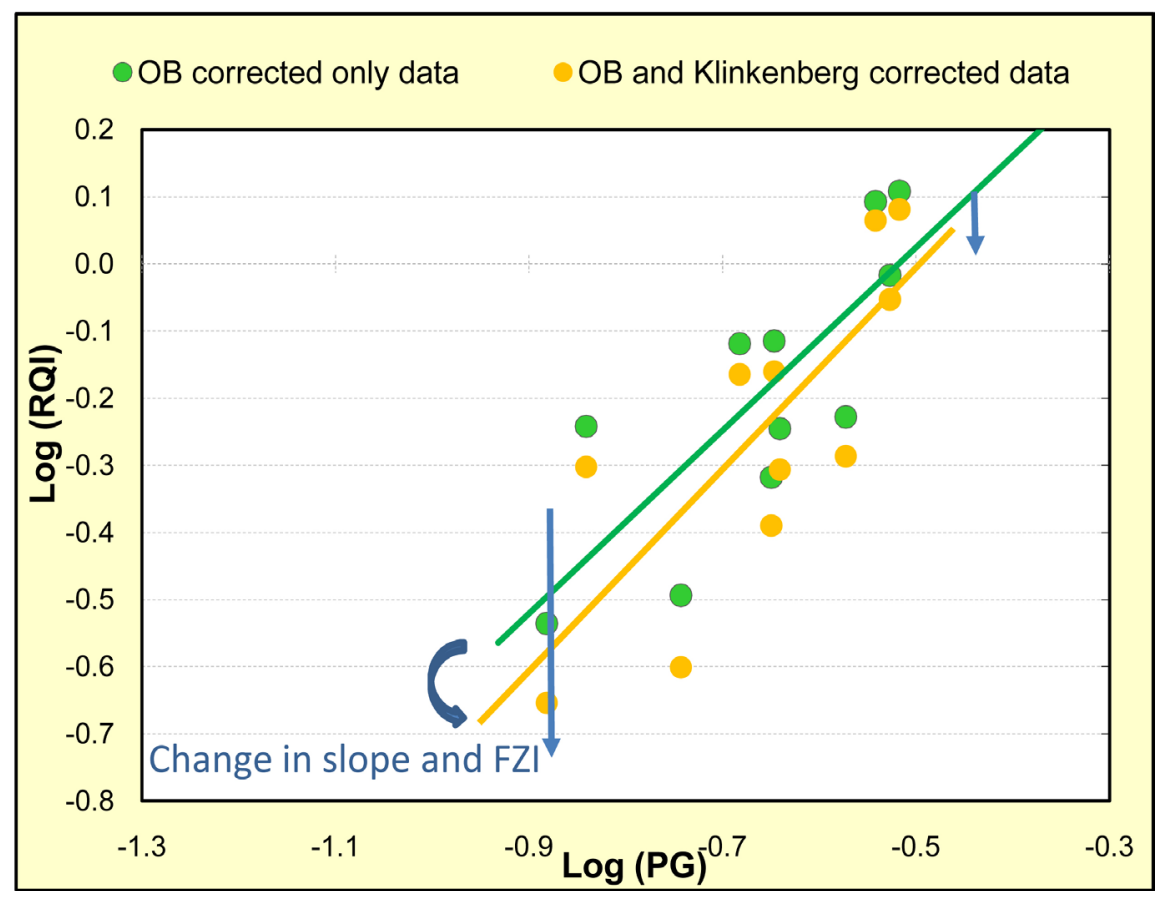

Figure 8. Conceptual example showing the effect of OB correction on HFZU analysis. 
of the corrections noted above. This analysis was guided by core photos, detailed core description, core photo-micrographs and scanning electron micrographs. A total of 19 HFZUs were identified for further study of OB and Klinkenberg correction effects, as summarised in Table 1. Three cases are indicated for each hydraulic unit: uncorrected data, $O B$ corrected and fully corrected data. It should be noted that HFZU that are deemed to be C-K compliant have a slope of $0.75-1.25$, where the exact range is somewhat arbitrary.

As indicated above, the change in slope due to $\mathrm{OB}$ correction is insignificant (average change less than 2\%). The FZI value increases by less than 5\% for OB correction alone. The specifics would be dependent on reservoir and laboratory testing conditions. A larger difference between ambient and OB pressures would yield a larger increase in FZI value.

Klinkenberg correction, on the other hand, may lead to more significant changes in both, the correlation and FZI values of individual HFZUs. For the case of Lam-2, the average increase in slope is $12 \%$, while the average FZI decreases by $10 \%$. Again, the precise statistics depend on specific lab and reservoir conditions, as well as the (range of) samples.

\section{Summary and Conclusions}

The following conclusions may be drawn:

Table 1. HFZU analysis for the Lam-2 well, indicating the impact of data corrections.

\begin{tabular}{|c|c|c|c|c|c|c|c|c|c|c|c|}
\hline \multicolumn{2}{|c|}{ Depth (m) } & \multirow[t]{2}{*}{ HFZU } & \multicolumn{3}{|c|}{ Uncorrected } & \multicolumn{3}{|c|}{ OB Corrected Only } & \multicolumn{3}{|c|}{ OB and Klinkenberg corrected } \\
\hline From & To & & Type & Slope & FZI & Type & Slope & FZI & Type & Slope & FZI \\
\hline 3210.22 & 3215.65 & 1 & $\mathrm{C}-\mathrm{K}$ & 1.10 & 3.984 & $\mathrm{C}-\mathrm{K}$ & 1.08 & 4.08 & $\mathrm{C}-\mathrm{K}$ & 1.20 & 3.72 \\
\hline 3215.9 & 3218.5 & 2 & $\mathrm{C}-\mathrm{K}$ & 1.21 & 6.417 & $\mathrm{C}-\mathrm{K}$ & 1.22 & 6.66 & $\mathrm{C}-\mathrm{K}$ & 1.30 & 6.20 \\
\hline 3218.91 & 3224.5 & 3 & Non-C-K & 2.55 & 12.419 & Non-C-K & 2.52 & 13.10 & Non-C-K & 2.60 & 12.67 \\
\hline 3232.33 & 3237.4 & 5 & Non-C-K & 2.76 & 2.818 & Non-C-K & 2.75 & 2.85 & Non-C-K & 3.43 & 2.22 \\
\hline 3243.95 & 3250.65 & 6 & Non-C-K & 2.42 & 8.564 & Non-C-K & 2.35 & 9.38 & Non-C-K & 2.74 & 8.05 \\
\hline 3250.9 & 3254.25 & 7 & $\mathrm{C}-\mathrm{K}$ & 1.21 & 14.197 & $\mathrm{C}-\mathrm{K}$ & 1.18 & 15.12 & $\mathrm{C}-\mathrm{K}$ & 1.24 & 14.46 \\
\hline 3254.45 & 3258.1 & 8 & $\mathrm{C}-\mathrm{K}$ & 0.93 & 6.865 & $\mathrm{C}-\mathrm{K}$ & 0.92 & 7.12 & $\mathrm{C}-\mathrm{K}$ & 0.97 & 6.75 \\
\hline 3265.41 & 3270.96 & 10 & Non-C-K & 2.79 & 6.609 & Non-C-K & 2.27 & 6.86 & Non-C-K & 3.03 & 6.18 \\
\hline 3271.15 & 3276.45 & 11 & Non-C-K & 2.27 & 1.794 & Non-C-K & 2.25 & 1.81 & Non-C-K & 2.83 & 1.25 \\
\hline 3276.8 & 3279.45 & 12 & Non-C-K & 3.06 & 0.997 & Non-C-K & 3.25 & 1.00 & Non-C-K & 4.66 & 0.59 \\
\hline 3279.79 & 3284.41 & 13 & Non-C-K & 1.35 & 2.897 & Non-C-K & 1.36 & 2.93 & Non-C-K & 1.55 & 2.55 \\
\hline 3284.6 & 3294.9 & 14 & $\mathrm{C}-\mathrm{K}$ & 1.04 & 18.949 & $\mathrm{C}-\mathrm{K}$ & 1.01 & 20.12 & $\mathrm{C}-\mathrm{K}$ & 1.04 & 19.54 \\
\hline 3297.45 & 3300.44 & 15 & Non-C-K & 2.95 & 17.717 & Non-C-K & 2.89 & 18.76 & Non-C-K & 2.99 & 18.18 \\
\hline 3309.8 & 3312.45 & 16 & Non-C-K & 1.98 & 3.873 & Non-C-K & 2.01 & 3.96 & Non-C-K & 2.20 & 3.50 \\
\hline 3315.66 & 3322.8 & 17 & $\mathrm{C}-\mathrm{K}$ & 1.22 & 10.458 & $\mathrm{C}-\mathrm{K}$ & 1.21 & 10.98 & $\mathrm{C}-\mathrm{K}$ & 1.25 & 10.57 \\
\hline 3359.1 & 3365.7 & 18 & Non-C-K & 1.96 & 8.275 & Non-C-K & 2.02 & 8.60 & Non-C-K & 2.15 & 8.13 \\
\hline 3365.99 & 3369.31 & 19 & Non-C-K & 1.81 & 5.929 & Non-C-K & 1.83 & 6.14 & Non-C-K & 1.99 & 5.66 \\
\hline
\end{tabular}


1) Overburden correction decreases both permeability and porosity of the samples, typically resulting in small increases in FZI values, but does not have a significant impact on the slope of HFZU relationships.

2) Klinkenberg correction decreases the permeability values (only), typically resulting in more significant modifications in both: the correlation and FZI values of HFZUs, especially for intervals that include low permeability samples.

3) It is important to perform Overburden and Klinkenberg correction (where appropriate) before final HFZU analysis, in particular when integrating SCAL plugs.

\section{Acknowledgements}

The authors acknowledge the early work by Chengzhi Yuan and Nhan B Truong in studying many data sets and deriving suitable $\mathrm{OB}$ correction correlations and experimenting with Klinkenberg corrections.

\section{References}

[1] Barr, D.C. and Altunbay, M. (1992) Identifying Hydraulic Units as an Aid to Quantifying Depositional Environments and Diagenetic Facies. Geology of Malaysia, Symposium Res. Evaluation/ Form. Damage, Kuala Lumpur, Malaysia.

[2] Amaefule, J.O., Altunbay, M., Tiab, D., Kersey, D.G. and Keelan, D.K. (1993) Enhanced Reservoir Description: Using Core and Log Data to Identify Hydraulic (Flow) Units and Predict Permeability in Uncored Intervals/Wells. Proceedings of the ATCE, 3-6 October 1993, Houston, Texas, USA.

[3] Kozeny, J. (1927) Über Kapillare Leitung des Wassersim Boden. Sitzungsberichte: Royal Academy of Science, Vienna.

[4] Carman, P.C. (1938) Fluid Flow through Granular Beds. J SocChemInd, 57, 225.

[5] Carman, P.C. (1937) Fluid Flow through Granular Beds. AIChE, 15, 150.

[6] Nooruddin, H., Hossain, M.E., Sudirman, S.B. and Sulaimani, T. (2001) Field Application of a Modified Kozeny-Carmen Correlation to Characterize Hydraulic Flow Units. Proceedings of the Saudi Arabia Section Technical Symposium and Exhibition, 15-18 May 2011, Al-Khobar, Saudi Arabia.

[7] Behrenbruch, P. and Biniwale, S. (2004) Characterisation of Clastic Depositional Environments and Rock Pore Structures Using the Kozeny-Carman Equation: Australian Onshore and Offshore Sedimentary Basins. JOPSE, 2005.

[8] Biniwale, S. and Behrenbruch, P. (2004) The Mapping of Hydraulic Flow Zone Units and Characterisation of Australian Geological Depositional Environments. Proceedings of the APOGCE, 18-20 Oct 2004, Perth, Australia. https://doi.org/10.2118/88521-ms

[9] Biniwale, S. and Behrenbruch, P. (2005) An Improved Approach for Modelling Geological Depositional Characteristics and Fluid Saturations by Using Hydraulic Units: Australian Offshore Fields. Proceedings of the SPWLA 46th Annual Logging Symposium, 26-29 Jun 2005, New Orleans, USA.

[10] Behrenbruch, P., Do Huu, M.T. and Bui, K. (2017) Optimal Zonation of Geological Formations and Identification of Pore Structures, including Variation in Cementation and Fining Sequences. Proceedings of the SPG, 26-28 Feb 2017, Sanya.

[11] Klinkenberg, L.J. (1941) The Permeability of Porous Media to Liquid and Gases. API Drilling and Production Practice, 200-213. 
[12] Florence, F.A., Rushing, J.A., Newsham, K.E. and Blasingame, T.A. (2007) Improved Pearmeability Prediction Relations for Low Permeability Sands. Proceedings of the Rocky Mountain Oil \& Gas Technical Symposium, 16-18 April 2007, Denver, USA.

[13] Hoang, T.G., Behrenbruch, P. and Do Huu, P. (2017) Correction of Laboratory Gas Permeability Measurements Using Klinkenberg Type Correction Models. Proceedings of the APPEA Conference and Exhibition, 14-17 May 2017, Perth, Australia.

\section{Nomenclature}

a =Lithology factor in Nooruddin et al. equation

FZI =Flow Zone Indicator

$\mathrm{F}_{\mathrm{s}} \quad=$ Pore throat shape factor

$\mathrm{H}_{\mathrm{c}} \quad=$ Kozeny pore structure parameter

$\mathrm{k}=$ =Absolute permeability

$\mathrm{k}_{\mathrm{Amb}} \quad=$ Ambient permeability

$\mathrm{k}_{\mathrm{OB}} \quad=$ Overburden corrected permeability

$\log =$ Logarithm base 10

$\mathrm{m}=$ Cementation factor in Nooruddin et al. equation

RCA = Routine Core Analysis

RQI =Reservoir Quality Index (or hydraulic radius)

$\mathrm{R}^{2} \quad=$ Standard measure of accuracy in fitting a relationship

SCAL $\quad=$ Special Core Analysis

$\mathrm{S}_{\mathrm{gv}} \quad=$ Surface area to grain volume ratio

$\phi \quad=$ Porosity

$\phi_{\text {Amb }} \quad=$ Porosity at ambient conditions

$\phi_{e} \quad=$ Effective porosity

$\phi_{O B} \quad=$ Porosity at overburden conditions (elevated pressure)-measured or from correlation

$\phi_{\mathrm{Z}} \quad=$ Porosity group, $\phi /(1-\phi)$

$\phi \quad=$ Tortuosity 
Submit or recommend next manuscript to SCIRP and we will provide best service for you:

Accepting pre-submission inquiries through Email, Facebook, LinkedIn, Twitter, etc. A wide selection of journals (inclusive of 9 subjects, more than 200 journals)

Providing 24-hour high-quality service

User-friendly online submission system

Fair and swift peer-review system

Efficient typesetting and proofreading procedure

Display of the result of downloads and visits, as well as the number of cited articles Maximum dissemination of your research work

Submit your manuscript at: http://papersubmission.scirp.org/

Or contact gep@scirp.org 